\title{
Meme Kanserli Bireylerde Manevi Bakımda Hemşirenin Rolü
}

\author{
The Role of Nurses in Spiritual Care in Patients with Breast Cancer
}

\author{
Şule Olgun 1 @ \\ ${ }^{1}$ T.C. İzmir Kavram Meslek Yüksekokulu, İzmir, Türkiye
}

ÖZ

\begin{abstract}
Fiziksel olarak gelişen bir hastalık beraberinde sosyal ve psikolojik sorunları da getirmektedir. Benzer şekilde ruhsal ve duygusal alandaki dalgalanmalarda, fiziksel açıdan bireyde patolojik sorunlara yol açabilmektedir. Bu nedenle günümüzde hastalar sadece fizyolojik açıdan değil, kültürel, ekonomik, duygusal, manevi ve sosyal yönden de ele alınmaktadır. Hemşireler bireylerin/hastaların biyolojik, psikolojik, sosyal ve manevi durumlarına ve gereksinimlerine göre bakım vermeli ve onların manevi gereksinimlerini karşılamada aktif rol almalıdır. Kanser hastalarının tedavi sürecinde maneviyatın olumlu bir etkisi olmaktadır. Özellikle meme kanserli bireylerin tedavi süresince zor deneyimlerle baş edebilmeleri için desteklenmesinde hastalarla en sık iletişim içerisine giren ve bakımlarından sorumlu olan sağlık çalışanları arasında hemşirelere büyük sorumluluk düşmektedir. Hemşireler meme kanserli hastalara manevi destek verebilmek amacıyla; hastayı yaşama bağlayacak empati ve şefkati gösterebilmeli bunun için de öncelikle hastanın manevi öyküsünü öğrenmelidir. Hemşirelerin hastalara manevi destek sağlayabilmeleri için maneviyat konusu ve önemi hakkında farkındalık kazanmaları çok önemlidir. $\mathrm{Bu}$ bilgilerden yola çıkarak hazırlanan derlemede; meme kanserli bireylerde manevi bakımda hemşirelere düzen görevlerin neler olduğu ve manevi bakımın meme kanserli hastalar üzerindeki etkisi literatür bilgilerinden yararlanılarak açıklanmıștır.
\end{abstract}

Anahtar Kelimeler: Meme kanseri, Manevi bakım, Hemşire.

\section{ABSTRACT}

A physically developing disease brings along social and psychological problems. Similarly, fluctuations in the mental and emotional field can lead to physical pathological problems in the individual. Therefore, patients are not only treated physiologically but also culturally, economically, emotionally, spiritually and socially. Nurses should provide care according to the biological, psychological, social and spiritual conditions and needs of individuals/patients and take an active role in meeting their spiritual needs. Spirituality has a positive effect on the treatment of cancer patients. Nurses have a great responsibility among the healthcare professionals who are in contact with the patients and who are responsible for their care, especially in supporting breast cancer individuals to cope with difficult experiences during the treatment. In order to provide moral support to breast cancer patients, nurses; show empathy and compassion that will connect the patient to life, and therefore must first learn the patient's spiritual history. It is very important for nurses to gain awareness of the spiritual issue and its importance in order to provide patients with moral support. In the review prepared based on this information; What are the regular duties for nurses in breast cancer individuals and the effects of spiritual care on breast cancer patients are explained by using the literature.

Key Words: Breast cancer, Spiritual care, Nurse.

\section{GİRIŞ}

Sağlık; beden, beyin ve ruh arasındaki uyum olarak da ifade edilebilir. Hastalık sadece fiziksel ve fonksiyonel olarak anormal değişikliklere sebep olmaz aynı zamanda bireyi psikososyal yönden de etkiler. Ölümle sonuçlanma insidansı yüksek olan hastalıklar, hastada genellikle manevi distrese sebep olur. Literatürde hastalıklar ile başetme yöntemlerinden biri maneviyat ve inanç olan hastaların ruhsal ve fiziksel sağlıklarında iyileşme görüldüğü 
belirtilmektedir (1-5). Hastalar ile hastane içerisinde en yakın ilişki içerisinde bulunan sağlık çalışanları hemşirelerdir. Hemşireler sadece fiziksel ağrıyı dindirmekten ya da fiziksel sorunların bakımından sorumlu değil aynı zamanda bireyin bütüncül bakımından da sorumludur. Bu nedenle maneviyat ve bütüncül bakım da hemşirelik kuramları içerisindedir.

Hemşireler meme kanserli hastalara manevi destek verebilmek amacıyla; hastayı yaşama bağlayacak empati ve şefkati gösterebilmeli bunun için de öncelikle hastanın manevi öyküsünü öğrenmelidir (6-8). Kemoterapi, radyoterapi, hormonal ve cerrahi tedaviye bağlı olarak ortaya çıkan fiziksel ve ruhsal sorunlar, bunun yanı sıra aile ve iş yaşamı ile ilgili sorunlar, geleceğe yönelik belirsizlikler, sosyal ve manevi sorunlar meme kanserli hastaların iyilik halini ve uyumunu olumsuz olarak etkilemektedir. Meme kanserinin hastalarda geniş yelpazede sorunlar yaratması, tedavi ve bakımın çok yönlü yaklaşımlarla ele alınmasını gerektirmektedir (9).

\section{Genel Bilgiler}

Hastalık ailesel, çevresel ve ruhsal yönden çok boyutlu ele alınan bir kimlik, varoluş ve yaşam krizidir (10). Fiziksel olarak gelişen bir hastalık beraberinde sosyal ve psikolojik sorunları da getirmektedir. Benzer şekilde ruhsal ve duygusal alandaki dalgalanmalarda, fiziksel açıdan bireyde patolojik sorunlara yol açabilmektedir. Bu nedenle günümüzde hastalar sadece fizyolojik açıdan değil, kültürel, ekonomik, duygusal, manevi ve sosyal yönden de ele alınmaktadır (8,11). Dünya Sağlık Örgüt'ü sağlığın tanımını yaparken; "Bireyin biyopsikososyal ve manevî yönden tam bir iyilik halinde olmasıdır" şeklinde ifade kullanmaktadır. Bu sebeple bireyde tam bir iyilik halinin sağlanabilmesi için maneviyat dâhil bütün bakım türlerinin hayata geçirilmesi gerekmektedir. Uluslararası Hemşireler Birliği (ICN) bireyin manevî boyutuna yönelik bakım hizmetlerinin verilmesinin hemşirelik bakımının bir parçası olduğunu ifade etmekte ve sağlık için manevi gereksinimlerin vücudu oluşturan fiziksel organlar kadar önemli bir öğe olduğunu vurgulamaktadır (12).

Manevi Bakım, 01.08.1998 tarihli 23420 sayılı Resmi Gazetede yayınlanan Hasta Hakları Yönetmeliği'nin 38. maddesinde "Hastanelerde yatarak tedavi gören hastaların tıbbi tedavilerine hiç bir şekilde müdahalede bulunulmamak şartı ile talep eden hastalara manevi telkinde bulunmak, onları ruhsal (manevi) ve moral yönünden desteklemek, ibadetlerini hastalıklarının verdiği imkânlar çerçevesinde yerine getirmelerine rehberlik etmek ve yaşama dirençlerini desteklemek amacıyla sunulan manevi destek hizmeti” olarak tanımlanmıştır $(12,13)$. Manevi bakımın dini ritüelleri yerine getirmenin yanında aynı zamanda yaşamın anlamını ve amacını algılamayı da içerdiği belirtilmiştir (14).

Kanserli hastanın uyumunda da bir dizi tıbbi, psişik ve psikososyal faktör rol oynamaktadır. Literatür gözden geçirildiğinde, meme kanserli hastaların uyumunda ise benlik saygıs1, sosyal stres, sosyal destek, psikolojik destek, kontrol duygusu, duygusal sorunlar, hastalığın evresi, ameliyat tipi, hastalık belirtileri, fiziksel yeterlilik durumu, hastalığa yönelik algılar, baş etme yöntemleri, sağlık profesyonelleriyle ilişkiler ve işbirliği gibi faktörlerin etkili olduğu bildirilmiştir (9). Meme kanseri kadınlar arasında görülen en önemli sağlık sorunlarından biridir ve ülkemizde kadınlarda görülen kanserler arasında birinci sırada yer almaktadır (15). Her yıl tüm dünyada meme kanseri görülme oranının arttığı bildirilmekte, buna karşın meme kanserinden ölüm oranı aynı düzeyde artmamaktadır. Bu durum yaşam süresinin uzamasıyla bağlantılı olarak hastaların yaşam kalitesi ve psikososyal uyumu ile ilgili çeşitli 
sorunları gündeme getirmektedir (16). Bir kadın için meme kanseri tanısı almak yıkıcı bir olaydır ve fiziksel problemlerin yanı sıra psikolojik, sosyal, mesleki ve varoluşsal yönden çeşitli sorunlara neden olmaktadır. Ayrıca meme kanserinde bu sürece, meme cerrahisi sonrasında kadınların bedenlerine güvenlerini kaybetmeleriyle sonuçlanan bedensel ve cinsel sorunlar da eklenmektedir (17).

Romero ve arkadaşları (2006) yaptıkları araştırmada kanser hastalarının; çoğunlukla sigara içme, tedavi için hastaneye başvurma süresi, beslenme şekli, tedavi sırasındaki davranışlarına ve tedavi haricindeki diğer alternatif yöntemlere başvurma ya da reddetme davranışları ile ilgili kendilerini suçladıklarını, suçluluk duygusuyla ise manevi yöntemlerle başettiklerini belirlemiştir. Birey hastalanınca "Neden ben? Bunu hak etmek ve yaşamak için ben ne yaptım? Yaradan beni cezalandırıyor mu? Ben öldükten sonra bana ne olacak? Ben öldükten sonra ailem nasıl yaşayacak? Yokluğum fark edilecek mi? Özlenecek miyim? Hatırlanacak mıyım? Hayatımdaki işlerimi bitirmek için yeterli zamanım olacak mı?” gibi soruları kendisine sormaktadır (19).

Culliford (2002) yaptığı araştırmada kanser hastalarının tamamına yakınının (\%93.0) manevi başetme yöntemleri ile umutlarını sürdürdüklerini belirlemiştir. Yapılan araştırmalar göstermektedir ki kanser hastalarının tedavi sürecinde maneviyatın olumlu bir etkisi olmaktadır $(1,3,5,6,21)$. Kanser hastaları tanı ve tedavi süresince yaşadıkları ruhsal bunalımı atlatmaları için ruh sağlıklarının ve motivasyonlarının normalde olduğundan daha güçlü olması ve bunun için de mutlaka bir sağlık çalışanından psikososyal destek almaları gerekmektedir (22).

Hastanede sağlık çalışanları içerisinde hastalarla sıklıkla yakın ilişki içerisine giren, hastalarına tanı ve tedavi süresi boyunca yanında olup, bütüncül bakım sunan hemşirelerdir ve bu aşamada hemşirelere büyük bir görev düştüğü düşünülmektedir. Ayrıca hemşireler tarafından sağlanan manevi desteğin koroner kalp hastalığı, hipertansiyon, felç, yüksek kolesterol, immünolojik bozukluklar, HIV ve diğer cinsel yolla bulasan hastalıklar ve çoğu kanser türlerinde olumlu etkilerinin olduğu da yapılan çalışmalarda belirtilmektedir (1,5,20,21,23-25). Hemsireler bireylerin/hastaların biyolojik, psikolojik, sosyal ve manevi durumlarına ve gereksinimlerine göre bakım vermeli ve onların manevi gereksinimlerini karşılamada aktif rol almalıdır $(7,8,14)$.

Birey hastalandığında geleceği ile ilgili belirsizliğe düşebilir, hastalığı ve tedavi sürecine uyum sağlamada sorunlar yaşayabilir. Bu aşamada hastanın yanında olup, ona moral ve motivasyon ile psikolojik destek sağlayacak olan, hastanın tedaviye uyumunu arttırıp, devamlılığını sağlayacak olan ve sonuçta hastanın yaşam kalitesini yükseltecek olan hemşirelerdir (26,27). Uluslararası Hemsirelik Konseyi Etik Kuralı'nda da (International Council of Nurses Code of Ethics) hemşirelerin "bireyin, ailenin ve toplumun insan hakları, değerleri, gelenekleri ve manevi inançlarına saygı göstermelidir” rolü açıkça belirtilmektedir. Sağlık çalışanlarının hastasına manevi bakım vermeden önce birtakım sorular sorarak değerlendirmede bulunması bunun için de aşağıda ifade edilen soruları sorarak veri toplaması gerekmektedir.

- Maneviyatın sizin için önemi nedir? Açıklar mısınız?

- Maneviyatınızı tanımlamanız gerekse nasıl tanımlarsınız?

- Günlük yaşamınızda yerine getirdiğiniz ibadetleriniz var mı?

- Belirli aralıklarla yinelediğiniz manevi uygulamalarınız var mı? 
- Kim ya da ne size güç ve ümit sağlar?

- Sahip olduğunuz manevi değerlerinizi kendiniz için kişisel bir güç olarak görüyor musunuz?

- Karşılaştığınız zorluklarla baş edebilmek için uyguladığınız manevi uygulamalar ya da ritüelleriniz var $\mathrm{m} 1$ ?

- Manevi değerleriniz karşılaştı̆̆ınız zorluklarla baş edebilmenizde ne şekilde size yardımc1 oluyor?

- Sizin için yaşamı daha anlamlı kılan bir gruba üyeliğiniz var mı?

- İnanç topluluğunuz, size yardımcı olduğunu düşündügünüz kaynaklar sunuyor mu?

- Yaratıcı ile da ilişkinizi nasıl tanımlarsınız?

- Yaşam felsefeniz nedir?

- Sağlık çalışanlarından beklediğiniz manevi/dini destek nasıldır?

- “Acı çekmek" sizin için ne anlam ifade eder?

- Ölüm kavramı sizin için ne anlam ifade eder?

- Manevi gereksinimleriniz nelerdir?

- Hastalıkla baş edebilmenizde inançlarınız size nasıl yardımcı olmaktadır?

- Sizi ve ailenizin yaşamını hastalık süreci nasıl etkilemektedir?

- Şimdiki durumunuzu açıklamanızda düşüncelerinizi şekillendiren bir inanış, bir felsefe, bir yaklaşım varsa benimle paylaşır mısınız?

Bakımınıza yön vereceğini düşündüğünüz farklı manevi konular var ise benimle paylaşmak ister misiniz? $(28,29)$.

Kanser hastaları hastalıkları ile başetmede manevi boyutlarını desteklemek amacıyla; inançlarını yazıya dökme, paylaşma, başkalarının ettikleri duaları dinleme, inançlarını geliştirme amacıyla toplantılara katılma, dua etme, inancı ile ilgili konuşma ve dini açıdan kutsal mekanları ziyaret etme gibi stratejiler geliştirmektedirler (30). Hemşireler meme kanserli hastalara manevi destek verebilmek amacıyla; hastaların korkularını, acılarını, umutlarını ve hayallerini bilmeli ve hastanın ifadelerini önyargısız kabul edebilmelidir. Meme kanserli hastalara bakım sunan hemşirenin; inançlar ve hastalığın anlamını etkileyen değerler hakkında bilgi sahibi olması ve bu doğrultuda hastasının fiziksel, duygusal ve manevi yönlerinin tamamını kapsayacak şekilde dikkatli ve destekleyici bir bakım sunması gerekmektedir. Hasta mensup olduğu dine yönelik uygulamaları yerine getirmek istiyorsa, yardımcı olmalı, hastasının inancını gerçekleştirebilmesi konusunda zaman ve mekan sağlanmasında yardımcı olmalı eğer hasta talepte bulunursa imam veya papaz gibi diğer profesyonel din adamlarına yönlendirmelidir. Ayrıca hemşire, hasta için manevi değer taşıyan bir eşya varsa, saygı göstermelidir (6-8).

Hastaya manevi destek olma sürecinde, geçmişte yaşadığı benzer deneyimlerde kullandığı başetme yöntemleri, rahatlama metotları sorularak ve bu yöntemler hatırlatılarak da destek olunabilir. Hasta için önemli olan bir sembol ya da eşya varsa tedavisi sırasında ya da en çok kaygıya sebep olabilecek süreçlerden biri olan cerrahi müdahale sırasında üzerinde taşımasına ya da yanında bulundurmasına imkan sunulabilir (31). Tüm bunların yanında hemşireler hastaları ile konuşmaya zaman ayırmalı, pozitif ve dürüst bir davranış sergileyerek hastaların bakım süreci ile ilgili sorularını sonuna kadar dinleyerek cevaplandırmalıdır (27). 
Literatürde hemşirelerin hastaların manevi bakımına yönelik aşağıdaki uygulamalarda bulunabileceği belirtilmektedir:

- Hastalara yaşama umudunu sağlamaya ve arttırmaya yönelik empatik ve şefkatli yaklaşım sergileme

- Hastaları fiziksel, duygusal ve manevi açıdan tüm yönleri ile ela alma ve buna yönelik bakım planı oluşturma

- Hastaların umutlarını, hayallerini, kaygılarını ve üzüntülerini ifade edebilmeleri için firsat tanıma ve kendilerini tarafsız olarak dinleme ve kabul etme

- Hasta ve ailelerinin manevi öykülerini öğrenme ve sağlıklarını biyopsikososyal açıdan tüm yönleri ile ele alma

- İnançlar ve hastalıklara kattıkları anlamlar hakkında güncel bilgilere sahip olma

- Hastalara dini vecibelerini yerine getirebilmeleri için uygun mekan, süre ve kaynağ sağlama ve bu uygulamalarını yerine getirmelerinde yardımcı olma

- Hastaların uygun olan manevi uygulamalarına katılma

- Hastalar için manevi önem taşıyan eşyalara saygı gösterme

- Hoca, imam veya papaz gibi diğer profesyoneller ile hastaların iletişiminin sağlanmasına yardımcı olma (6-8).

\section{SONUC}

Sonuç olarak, hastalık, acı çekme, ölüm gibi deneyimler zorlayıcı yaşam olayları arasındadır ve meme kanseri tanısı alan kadınların yarısına yakın bir kısmının tanıdan sonraki bir y1l içinde meme kanseri ile yaşamaya uyum sağlamakta güçlük çektiği ve dolayısıyla anksiyete ve depresyonun görüldüğü, uzun vadede ise kadınların yaşam kalitesinde ciddi bir azalma olduğu belirtilmektedir. Meme kanserli bireylerin bu zor deneyimlerle baş edebilmesi için desteklenmesinde hastalarla en sık iletişim içerisine giren ve bakımlarından sorumlu olan sağlık çalışanları arasında hemşirelerdir. Bu sebepledir ki hemşirelerin hastalara manevi destek sağlayabilmeleri için maneviyat konusu ve önemi hakkında farkındalık kazanmaları önemlidir (32).

Hemşire yetiştiren okulların ders programlarında bütüncül sağlık görüşüyle manevi bakım konusuna yer verilmesi, hizmet içi eğitim programlarıyla çalışan hemşirelerin de konuya dikkatinin çekilmesinin, bütüncül hasta bakımı kapsamında yararlı olacağı düşünülmektedir. Manevi bakımın kanserli bireylerin iyileşmesine ve rehabilitasyonuna katkısı konusunda araştırmalar yapılmasının sağlık personelinin manevi bakım konusunda duyarlılıklarını geliştirmede katkı sağlayacağı öngörülmektedir (33). Hasta bakımının manevi boyutunun ele alınması ve sağlık personelinin bu konuya dikkatinin çekilmesi konusunda ülkemizde daha kapsamlı çalışmalar yapılması gerekmektedir. Bu eksiklikten yola çıkarak bu makalenin literatüre katkı sağlayacağı düşünülmektedir.

\section{KAYNAKLAR}

1. Cotton, S. P., Levine, E. G., Fitzpatrick, C. M., Dold, K. H., \& Targ, E. (1999). Exploring the relationships among spiritual well-being, quality of life, and psychological adjustment in women with breast cancer. Psycho-oncology, 8(5), 429-438. 
2. Woods, T. E., \& Ironson, G. H. (1999). Religion spirituality in the face of illness: How cancer, cardiac, and HIV patients describe their spirituality/religiosity. J Health Psychol, 4(3), 393-412.

3. Boscaglia, N., Clarke, D. M., Jobling, T. W., \& Quinn, M. A. (2005). The contribution of spirituality and spiritual coping to anxiety and depression in women with a recent diagnosis of gynecological cancer. Int J Gynecol Cancer, 15(5), 755-761.

4. Frick, E., Riedner, C., Fegg, M., Hauf, S., \& Boraio, G. D. (2006). A clinical interview assessing cancer patients' spiritual needs and preferences. Eur J Cancer Care, 15(3), 238-243.

5. Choumanova, I., Wanat, S., Barrett, R., \& Kopman, C. (2006). Religion and spirituality in coping with breast cancer: Perspective of Chilean women. The Breast Journal, 12(4), 349-352.

6. Puchalski, C. M. (2001). The role of spirituality in health care. BUMC (Baylor University Medical Center) Proceedings, 14(4), 352-357.

7. Aştı, N., Pektekin, Ç., \& Adana, F. (2005). Cerrahi hemşirelik bakımının manevi boyutu. Hemsirelik Dergisi, 54, 27-34.

8. Baldacchino, D. (2006). Nursing competencies for spiritual care. J Clin Nurs. 15(7), 885-96.

9. Çam, O., Saka, Ş., \& Gümüş, G. A. (2009). Meme Kanserli Hastaların Psikososyal Uyumlarını Etkileyen Faktörlerin İncelenmesi. Meme Să̆lı̆̆ Dergisi, 5(2).

10. Kaçmaz, N. (1999). Konsultasyon-Liyezon psikiyatrisi hemsireliği ve biyopsikososoyal bakım. Konsultasyon-Liyezon Psikiyatrisi 1998-1999 Kitabı. İstanbul, 198-208.

11. Tanyi, R. A. (2002). Towards clarification of the meaning of spirituality. $J$ Adv Nurs, 39(5), 500-9.

12. Başar, S. (2014). Hastanelerde Din Hizmeti Modeli, http://Www.Manevibakim.Com/Bilim_Alanlari/Manevi_Bakim/Makale_01.Asp (Erişim: 26.08.2020).

13. Çetin, G., (Edt.) \& Kaya, A. (Edt.) (2012). Hekimlik Uygulamalarının Adli Tibbi Güncellenmesi, İ.Ü. Cerrahpaşa Tıp Fak. Sürekli Tıp Eğitimim Etkinlikleri Sempozyum Dizisi No:78, İstanbul. (198-199)

14. Ergül, Ş., \& Temel, A. B. (2007). Maneviyat ve Manevi Bakım Dereceleme Ölçeği’nin Türkçe Formunun Geçerlilik ve Güvenirliği, Ege Üniversitesi Hemşirelik Yüksek Okulu Dergisi, 23(1), 75-87.

15. Türkiye Kanser İstatistikleri Yıllığı, 2017. http://kanser.gov.tr/ Erişim Tarihi: 09/06/2020.

16. Taleghani, F., Parsa Yekta, Z., \& Nasrabadi., A. N. (2006). Coping with breast cancer in newly diagnosed Iranian women. Journal of Advanced Nursing, 54(3), 265-273.

17. Bez, Y., Göçen, E., Kuşçu, M. K., Önen, P., Nurmedov, S., \& Mayadağl1, A. (2004). Mastektomi sonrası beden algısının depresyon, anksiyete ve yaşam kalitesi ile ilişkisi. 40. Ulusal Psikiyatri Kongresi, Program ve Özet Bildirileri Kitabı, İzmir.

18. Romero, C., Kalidas, M., Elledge, R., Chang, J., Liscum, K. R., \& Friedman.,. L. C. (2006). Self- forgiveness, spirituality, and psychological adjustment in women with breast cancer. J Behav Med, 29(1), 29-36.

19. Büssing, A., Ostermann, T., \& Matthiessen, P. (2005). Role of religion and spirituality in medical patients: Confirmatory results with the questionnaire. Health Qual Life Outcomes, 10, 1-10.

20. Culliford, L. (2002). Spirituality and clinical care. BMJ, 325, 1434-1435.

21. Narayanasamy, A. (2003). Spiritual coping mechanisms in choronic illness: A qualitative study. Br J Nurs, 11, 1461-1470. 
22. Bostanc1, Dastan, N., \& Buzlu, S., (2010). Meme Kanseri Hastalarında Maneviyatın Etkileri ve Manevi Bakım Maltepe Üniversitesi Hemsirelik Bilim ve Sanatı Dergisi, 3, 1.

23. Thoresen, C. (1999). Spirituality and health: Is there a relationship? J Health Psychol, 4(3), 291-300.

24. Koenig, H. G. (2003). Religion, spirituality and health: an American physician's response. Med J Aust, 178(2), 51-52.

25. Meraviglia, M. (2006). Effects of spirituality in breast cancer survivors. Oncol Nurs Forum, 33(1), 1-7.

26. Herth, K. (2000). Enhancing hope in people with a first recurrence of cancer. $J A d v$ Nurs, 32, 1431-1441.

27. Chi, G. C. H. L. (2007). The role of hope in patients with cancer. Oncol Nurs Forum, 34, 415-424.

28. Ergül, S., \& Bayık, A. (2004). Hemsirelik ve manevi bakım. Cumhuriyet Üniversitesi Hemsirelik Yüksekokulu Dergisi, 8(1), 37-45.

29. Hodge, D. R. (2005). Spiritual Ecograms: A new assessment instrument for 1dentify ingclients' spiritual strengths in space and across time. Families in Society, 86(2), 28796.

30. Vachon, M. L. S. (2008). Meaning, spirituality and wellness in cancer survivors. Semin Oncol Nurs, 24, 218-260.

31. Cimete, G. (2002). Yaşam Sonu Bakım. Istanbul, Nobel Tıp Kitabevleri, 125-35.

32. Hiçdurmaz, D., \& Öz, F. (2013). Stresle başetmenin bir boyutu olarak spiritüalite. Anadolu Hemşirelik ve Sağllk Bilimleri Dergisi, 16(1), 50-6.

33. Gönenç, M. İ., Akkuzu, G., Altın, D. R., \& Möroy, P. (2016). Hemşirelerin ve ebelerin manevi bakıma ilişkin görüşleri. Gümüşhane Üniversitesi Sağllk Bilimleri Dergisi, 5(3), 34-8. 